\title{
Dietary Protein Restriction in Established Renal Injury in the Rat Selective Role of Glomerular Capillary Pressure in Progressive Glomerular Dysfunction
}

\author{
K. A. Nath, S. M. Kren, and T. H. Hostetter \\ Department of Medicine, School of Medicine, University of Minnesota, Minneapolis, Minnesota 55455
}

\begin{abstract}
Dietary protein restriction imposed before renal injury is established in the remnant kidney model in the rat reduces glomerular hypertension and hyperperfusion and renal injury. We demonstrate that dietary protein restriction (6\% vs. $20 \%$ ) imposed on a background of established renal injury in the remnant model leads to a greater preservation of renal function as measured by glomerular filtration rate and fractional clearances of albumin and IgG, despite the persistence of systemic hypertension. In similarly prepared rats, dietary protein restriction (6\% vs. $20 \%$ ) led to a lower glomerular capillary hydraulic pressure, a higher ultrafiltration coefficient, and similar single nephron filtration rates. In addition, less impairment of glomerular permselectivity was demonstrable after protein restriction. Our data demonstrate that the preservation of renal function with dietary protein restriction after established glomerular injury follows upon reduction of glomerular capillary hydraulic pressure, despite constancy of single nephron filtration rate and plasma flow and persistence of arterial hypertension.
\end{abstract}

\section{Introduction}

Dietary protein restriction reduces renal injury in virtually all models of experimental renal disease (1-6). Studies in the remnant model of chronic renal failure in the rat have demonstrated that the institution of a low protein diet before renal injury is established greatly lessens the severity of various functional and structural indicators of damage $(1,2,7-10)$. Micropuncture studies of dietary protein restriction have highlighted its efficacy in markedly blunting the adaptive increases in single nephron filtration rates, plasma flow, and capillary pressure that attend reductions of renal mass (2), and have indicated that it is largely through such hemodynamic effects that a reduction in dietary protein diminishes the severity of chronic renal injury $(2,11,12)$.

Findings in the remnant model have generated optimism that the progression of human renal disease may be similarly slowed by a reduction in protein intake (12-14). Extrapolating from these studies in the remnant model to therapeutic strategies in chronic human disease may well be tenuous from several standpoints. Experimental studies in the remnant model have uniformly imposed dietary restriction before injury is established

Parts of this work have appeared in abstract form in 1985, Kidney Int., 27:248, and in 1985, Clin. Res. 33:494A. 1986.

Received for publication 10 June 1985 and in revised form 1 July

J. Clin. Invest.

(C) The American Society for Clinical Investigation, Inc.

0021-9738/86/11/1199/07 \$1.00

Volume 78, November 1986, 1199-1205
(2, 7-10), never after, and have often compared the restricted diet with one with high rather than standard protein content (2, 7-9). Finally, that renal function, measured as glomerular filtration rate $(\mathrm{GFR})^{1}$, is actually better preserved on a lower protein intake has not been previously demonstrated.

This study examines whether dietary protein restriction in the remnant kidney model of chronic renal failure would still exert protective effects on glomerular function if imposed after renal injury is already established, and whether such protective effects are attended by alterations in glomerular hemodynamics.

\section{Glossary}

ALB Albumin

$\overline{A P} \quad$ Mean femoral arterial pressure $(\mathrm{mmHg})$

$C \quad$ Protein concentration $(\mathrm{g} / \mathrm{dl})$

FF Filtration fraction

Hct Blood hematocrit in femoral artery or afferent arteriole (vol \%)

$K_{\mathrm{f}} \quad$ Glomerular ultrafiltration coefficient (nl/s-mmHg)

$P \quad$ Hydraulic pressure $(\mathrm{mmHg})$

$\overrightarrow{\Delta P} \quad$ Transcapillary hydraulic pressure gradient $\left(\bar{P}_{\mathrm{GC}}-P_{\mathrm{T}} \mathrm{mmHg}\right)$

$\pi \quad$ Colloid osmotic pressure $(\mathrm{mmHg})$

$Q_{\mathrm{A}} \quad$ Initial glomerular capillary plasma flow rate $(\mathrm{nl} / \mathrm{min})$

$R \quad$ Resistance to blood flow (dyn-s- $\mathrm{cm}^{-5}$ )

$R_{\mathrm{TA}} \quad R_{\mathrm{A}}+R_{\mathrm{E}}\left(\right.$ dyn-s-cm $\left.^{-5}\right)$

$S F P$ Stop-flow pressure ( $\mathrm{mmHg}$ )

$\theta_{\text {ALB }}$ Fractional clearance of albumin

$\theta_{\mathrm{IgG}} \quad$ Fractional clearance of IgG

\section{Superscript \\ - Mean value

$\begin{array}{ll}\text { Subscripts } \\ \text { A } & \text { Afferent arteriole } \\ \text { C } & \text { Peritubular capillary } \\ \text { E } & \text { Efferent arteriole } \\ \text { GC } & \text { Glomerular capillary } \\ \text { T } & \text { Proximal tubule }\end{array}$

\section{Methods}

Long-term studies. 12 male Sprague-Dawley rats weighing $225-250 \mathrm{~g}$ were subjected to approximately one and two-thirds subtotal nephrectomy by removal of the right kidney and selective segmental infarction of the left kidney under methohexithal anesthesia $(5 \mathrm{mg} / 100 \mathrm{gm}$ body wt) administered by intraperitoneal injection. All rats were maintained on standard rat chow (Ralston Purina Co., St. Louis, MO) and water ad libitum for $3 \mathrm{mo}$. Serum creatinine was then measured by a modification of the Jaffe reaction (15) on a creatinine analyzer 2, (Beckman Instruments, Inc., Fullerton, CA) from a tail vein blood sample. All animals were then housed in individual metabolic cages and all urine excreted over $24 \mathrm{~h}$ was collected under mineral oil. Urinary total protein excretion was assayed by the sulfosalicylic acid method (16). The day after metabolic

1. Abbreviations used in this paper: GFR, glomerular filtration rate; RPF, renal plasma flow; SNGFR, single nephron GFR. 
collections, systolic arterial blood pressure was measured with the tailcuff method, using a physiograph (model MK-IV, Narco Bio-Systems, Houston, TX).

Rats exhibiting urinary total protein excretory rates $>25 \mathrm{mg} / \mathrm{d}$ were then paired into two groups based on serum creatinine, thus ensuring similar levels of renal function. One group was maintained on a $6 \%$ protein diet (Teklad diet No. TD83437, Teklad, Madison, WI) while the other group was maintained on a $20 \%$ protein diet (Teklad diet No. 170597) and water ad libitum for an additional $3 \mathrm{mo}$. These two diets were isocaloric and had identical electrolyte and lipid contents. They differed only in protein contents and in the sucrose added to the $6 \%$ diet to ensure that both diets were isocaloric.

Systolic arterial pressure was measured by the tail-cuff method at monthly intervals, after division into the two dietary groups. Urine collections over $24 \mathrm{~h}$ were repeated after all animals were on their respective diets for 3 mo. After this, clearance studies were performed. Rats were anesthetized with Inactin, $(100 \mathrm{mg} / \mathrm{kg}$ body wt administered by intraperitoneal injection; BYK Gulden, Konstanz, Federal Republic of Germany) and placed on a temperature-regulated table. A PE-50 polyethylene catheter was inserted into the left femoral artery for blood sampling and for blood pressure monitoring via a pressure transducer (model P23 Db, Statham Instruments, Oxnard, CA) connected to a duograph recorder (model 1CT-2H, Gilson Medical Electronics, Inc., Middleton, WI). After femoral artery catheterization, a blood sample was immediately taken for measurement of hematocrit and total plasma protein. Hematocrit was determined by a micro-capillary hematocrit reader (International Equipment Co., Neeham Heights, MA). Total plasma protein was determined by refractometry. The trachea was catheterized with PE-240 tubing and the left external jugular vein was catheterized with PE-50 for infusion. The left ureter was catheterized with PE-10 and urine was collected under mineral oil in a graduated glass tube. To determine GFR, a solution of normal saline containing methoxy $\left[{ }^{3} \mathrm{H}\right]$ inulin $(10 \mu \mathrm{Ci} / \mathrm{ml})$ was infused at a rate of $1.2 \mathrm{ml} / \mathrm{h}$ after a priming dose of $0.5 \mathrm{ml}$ over 5 $\mathrm{min}$. After allowing $30 \mathrm{~min}$ for equilibration, two clearance collections were performed. Radioactivity in the urine and the plasma were determined by liquid scintillation counting. Urinary and plasma levels for both IgG and albumin from samples collected during the clearance study were measured by rate nephelometry using an immunochemistry analyzer (Beckman Instruments, Inc.). Goat-derived anti-rat IgG and albumin (Cappel Laboratories, Malvern, PA) were used to generate the antigenantibody reaction used in their respective nephelometric reactions. Fractional clearances of albumin and IgG were calculated.

Histologic analysis of remnant kidney tissue was undertaken in six pairs of animals subjected to the experimental protocol of the long-term studies as detailed above. These animals were thus paired on the basis of serum creatinine determined 3 mo after subtotal nephrectomy, and one member of each pair was maintained on $6 \%$ protein while the other member of each pair was maintained on $20 \%$ protein for an additional $3 \mathrm{mo}$. Three of these six pairs comprised animals in which renal functional measurements were also performed. Animals were anesthetized with Inactin $(100 \mathrm{mg} / \mathrm{kg}$ body wt, given i.p.), the renal pedicle was clamped, and the remnant kidney was removed. The viable remnant kidney tissue was carefully dissected away from the renal scar, and then fixed in glacial acetic acid Zenker's solution. Sections were then cut at $5 \mu \mathrm{m}$ and stained with hematoxylin and eosin. Sections were examined in a coded blinded manner with regard to glomerular injury. $\mathbf{5 0}$ glomeruli were sequentially scored, by repeatedly scanning the cortex from the outermost cortex to the cortico-medullary junction. Normal glomeruli, glomeruli exhibiting segmental sclerosis, and glomeruli that were globally sclerosed were assigned scores of 0,1 , and 2 respectively.

Short-term studies. To assess the early effects of dietary protein manipulation on renal hemodynamics in already damaged remnant kidneys, we studied a second group of 10 male Sprage-Dawley rats, weighing 275$300 \mathrm{~g}$, subjected to one and two-thirds subtotal nephrectomy as previously described, and maintained on standard rat chow and water ad libitum for $6 \mathrm{wk}$. Animals were then divided into two groups, matched for serum creatinine as in the long-term studies. Urinary protein excretory rates were also measured. These groups were then maintained on either a $6 \%$ protein diet (Teklad No. TD83437) or a $20 \%$ protein diet (Teklad No. 170597) and tap water for a further 2 wk, after which clearance and micropuncture studies were performed.

On the morning of micropuncture, rats were anesthetized with Inactin $(100 \mathrm{mg} / \mathrm{kg}$ body $\mathrm{wt}$, i.p.) and placed on a temperature-regulated table. The left femoral artery was catheterized and blood pressure recorded as described previously. A tracheostomy was performed and both external jugular veins were catheterized with PE-50 for infusion. All animals were infused with isoncotic rat plasma equal to $1 \%$ body wt to replace surgical losses and maintain constancy of initial hematocrit (17). The left ureter was catheterized with PE-10 and urine collected under mineral oil. To determine GFR and single nephron glomerular filtration rates (SNGFR), normal saline containing methoxy $\left[{ }^{3} \mathrm{H}\right]$ inulin $(100 \mu \mathrm{Ci} / \mathrm{ml})$ was infused at a rate of $1.2 \mathrm{ml} / \mathrm{h}$ after a priming dose of $0.5 \mathrm{ml}$ over $5 \mathrm{~min}$. Timed collections of proximal tubular fluid were obtained by micropuncture from proximal surface convolutions for determination of total radioactivity in a minimum of three tubules. Only normal-appearing tubules in which oil droplets flowed freely were used. A 23-gauge needle connected to a tuberculin syringe was inserted into the left renal vein to obtain renal vein samples. Filtration fraction was calculated from the extraction of inulin. Hydraulic pressure measurements were made in cortical tubules and efferent arterioles by the servo-null micropipette technique. Glomerular capillary pressure was measured indirectly by the stop-flow methodology using the servo-null micropipette technique (18). As in the collection of tubular fluid for the determination of SNGFR, only normalappearing tubules were used in determining tubular and stop-flow pressures. Values of proximal tubular, efferent arteriolar, and stop-flow pressures were the mean of at least three determinations for each rat. The details of the calculations are fully described below. Clearances of albumin and IgG were performed as outlined above.

Histologic analysis of glomerular injury was also assessed in these short-term studies. Another group of eight male Sprague-Dawley rats, weighing $275-300 \mathrm{~g}$, was subjected to a similar degree of renal ablation and maintained on standard rat chow for $6 \mathrm{wk}$. Animals were then paired into two groups as before, based on serum creatinine, and maintained on either 6 or $20 \%$ protein diets. After $2 \mathrm{wk}$ of dietary protein stratification, animals were anesthetized with Inactin, and the remnant kidney tissue was fixed at the ambient mean arterial pressure with $1.25 \%$ glutaraldehyde in $0.1 \mathrm{mM}$ sodium cacodylate buffer ( $\mathrm{pH} 7.4$, osmolality 300 mosmol). Sections were cut at $5 \mu \mathrm{m}$ and stained with hemotoxylin and eosin. Sections were scored in a coded blinded fashion for the degree of glomerular injury, performed in an identical fashion to the histological analysis detailed in the long-term studies.

Calculations. Glomerular capillary pressure:

$\bar{P}_{\mathrm{GC}}=\pi_{\mathrm{A}}+S F P$,

where osmotic pressure, $\pi_{\mathrm{A}}$, is calculated from the Landis Pappenheimer equation (19)

$\pi_{\mathrm{A}}=2.1 C+0.16 C^{2}+0.009 C^{3}$.

Mean glomerular transcapillary hydraulic pressure gradient:

$\overline{\Delta P}=\bar{P}_{\mathrm{GC}}-P_{\mathrm{T}}$

SNGFR:

SNGFR $=\frac{\text { tubular fluid counts } / \text { min }}{\text { plasma counts } / \text { nanoliter }}$.

Initial glomerular plasma flow rate:

$Q_{\mathrm{A}}=\frac{\mathrm{SNGFR}}{\mathrm{FF}}$.

Efferent arteriolar total plasma protein concentration:

$C_{\mathrm{E}}=\frac{C_{\mathrm{A}}}{1-\mathrm{FF}}$. 
Table I. Systolic Arterial Blood Pressure Measurements in Conscious Rats at Monthly Intervals after Diet Change

\begin{tabular}{llll}
\hline & First month & Second month & Third month \\
\hline & $m m H g$ & $m m H g$ & $m m H g$ \\
6\% protein & $141 \pm 4$ & $154 \pm 7$ & $153 \pm 7$ \\
$20 \%$ protein & $141 \pm 6$ & $150 \pm 6$ & $145 \pm 7$ \\
$P$ & NS & NS & NS \\
\hline
\end{tabular}

$n=6$

Blood flow rate per single afferent arteriole or glomerulus, GBF:

$\mathrm{GBF}=\frac{Q_{\mathrm{A}}}{1-H c t_{\mathrm{A}}}$.

Efferent arteriolar blood flow rate:

$\mathrm{EABF}=\mathrm{GBF}-\mathrm{SNGFR}$.

Resistance per single afferent arteriole:

$R_{\mathrm{A}}=\frac{\left(\overline{\mathrm{AP}}-\bar{P}_{\mathrm{GC}}\right.}{\mathrm{GBF}} \times\left(7.962 \times 10^{10}\right)$,

where the factor $7.962 \times 10^{10}$ is used to give resistance in dyn-s-cm ${ }^{-5}$ and $\overline{A P}$ and $\bar{P}_{\mathrm{GC}}$ are expressed in $\mathrm{mmHg}$ and GBF in nanoliters per minute. Resistance per single efferent arteriole:

$R_{\mathrm{E}}=\frac{\bar{P}_{\mathrm{GC}}-P_{\mathrm{C}}}{\mathrm{EABF}} \times\left(7.962 \times 10^{10}\right)$.

Total arteriolar resistance across the glomerulus:

$R_{\mathrm{TA}}=R_{\mathrm{A}}+R_{\mathrm{E}}$.

The mathematical model described by Deen et al. (20) was used to calculate the glomerular ultrafiltration coefficient, $K_{\mathrm{f}}$. This model determines the rate of change of protein concentration along an idealized glomerular capillary and requires the following input: $\overline{\Delta P}, Q_{\mathrm{A}}, C_{\mathrm{A}}$, and $C_{\mathrm{E}}$ for the calculation of $K_{\mathrm{f}}$.

Statistics. All data are presented as means \pm SEM. Urinary protein excretory rates were transformed into the natural logarithm before statistical analysis to correct for their nonparametric distribution (21). Paired data were analyzed with the paired $t$ test and differences were considered statistically significant for $P<0.05$.

\section{Results}

Long-term studies. 3 mo after subtotal nephrectomy, all rats appeared healthy. Groups destined to receive either a $6 \%$ or a $20 \%$ protein diet for an additional 3 mo were well matched for body weight ( $314 \pm 7$ vs. $302 \pm 15 \mathrm{~g}, P=\mathrm{NS})$, serum creatinine $(1.2 \pm 0.2$ vs. $1.4 \pm 0.2 \mathrm{mg} / \mathrm{dl}, P=\mathrm{NS})$, urinary total protein ex- cretory rates ( $51 \pm 11$ vs. $60 \pm 13 \mathrm{mg} / 24 \mathrm{~h}, P=\mathrm{NS})$, and systolic arterial pressure (145 \pm 7 vs. $140 \pm 7 \mathrm{mmHg}, P=\mathrm{NS}$ ) (all values $6 \%$ vs. $20 \%$ ). Thus, before dietary protein manipulation both groups exhibited comparable levels of renal dysfunction.

3 mo after division into the two levels of dietary protein, the mean body weight of rats maintained on $6 \%$ protein, measured at $294 \pm 6 \mathrm{~g}$, was statistically lower than the mean body weight of rats on $20 \%$ protein, $351 \pm 20 \mathrm{~g}(P<0.05)$. Hematocrit and total plasma protein in the rats fed $6 \%$ protein diet, $46 \pm 1 \%$ and $5.6 \pm 0.2 \mathrm{~g} / \mathrm{dl}$, respectively, were similar to these parameters in the rats fed $20 \%$ protein diet, measured at $43 \pm 2 \%$ and $5.8 \pm 0.1$ $\mathrm{g} / \mathrm{dl}$ respectively. However, dramatic differences were observed in urinary total protein excretory rates. Urinary total protein excretion in rats maintained on $6 \%$ protein, $7.0 \pm 1.0 \mathrm{mg} / 24 \mathrm{~h}$ was strikingly reduced compared with urinary total protein excretion in rats maintained on $20 \%$ protein determined at $36.0 \pm 4.0 \mathrm{mg} / 24 \mathrm{~h}(P<0.001)$. The reduction in proteinuria in remnant animals on switching from a standard rat chow to a synthetic $20 \%$ protein diet is a finding we have consistently observed and is likely due to the protein ( $24 \%$ vs. $20 \%)$ as well as other compositional differences, such as sodium $(0.49 \%$ vs. $0.08 \%$ ), between these two diets. Similarly, marked differences were also seen for urinary albumin and IgG excretory rates between the two dietary groups: rats maintained on $6 \%$ protein, excreted $2.3 \pm 1.0$ and $0.5 \pm 0.1 \mathrm{mg} / 24 \mathrm{~h}$ of urinary albumin and IgG respectively, which were values significantly lower than these parameters obtained in rats maintained on $20 \%$ protein, determined at $15.0 \pm 3.0$ and $4.8 \pm 1.5 \mathrm{mg} / 24 \mathrm{~h}$, respectively $(P$ $<0.001)$. These differences in urinary protein excretion were observed in the absence of any significant difference in conscious systolic arterial pressure at any time during the study (Table I).

Clearance studies performed 3 mo after dietary protein manipulation revealed higher inulin clearance in rats maintained on $6 \%$ protein, measured at $0.68 \pm 0.13 \mathrm{ml} / \mathrm{min}$ when compared with inulin clearances in rats maintained on $20 \%$ protein, measured at $0.40 \pm 0.12 \mathrm{ml} / \mathrm{min}(P<0.05$, Table II). In addition, fractional clearances of albumin and IgG in rats fed a $6 \%$ protein diet calculated at $42 \pm 14 \times 10^{-5}$ and $14 \pm 6 \times 10^{-5}$ were significantly lower than the corresponding values obtained in animals maintained on $20 \%$ protein, measured at $264 \pm 61 \times 10^{-5}$ and $73 \pm 32 \times 10^{-5}$, respectively (Table II). As with systolic pressures in the conscious state, there was no statistical difference in mean arterial pressure between the two dietary groups (Table II). Thus, 3 mo after dietary protein manipulation, despite established injury, rats fed a lower protein diet demonstrated greater preservation of renal function as indicated by a higher GFR and less evidence of renal injury as indicated by lower fractional clearances of albumin and $\mathrm{IgG}$.

In remnant animals in which histological analysis of kidney tissue was undertaken, levels of renal dysfunction were similar

Table II. Data Obtained in the Two Dietary Groups 3 mo after Diet Change

\begin{tabular}{|c|c|c|c|c|c|c|c|c|c|}
\hline & WT & HCT & $C_{\mathrm{A}}$ & $\overline{A P}$ & $\begin{array}{l}\text { Serum } \\
\text { creatinine }\end{array}$ & GFR & $\begin{array}{l}\text { Urinary total protein } \\
\text { excretion }\end{array}$ & & \\
\hline$n=6$ & $g m$ & $\%$ & $g / d l$ & $m m H g$ & $m g / d l$ & $\mathrm{ml} / \mathrm{min}$ & $m g / 24 h$ & $\theta_{A L B} \times 10^{-5}$ & $\theta_{15 G} \times 10^{-5}$ \\
\hline $6 \%$ protein & $294 \pm 6$ & $46 \pm 1$ & $5.6 \pm 0.2$ & $141 \pm 5$ & $1.12 \pm 0.11$ & $0.68 \pm 0.13$ & $7.0 \pm 1.0$ & $42 \pm 14$ & $14 \pm 6$ \\
\hline $20 \%$ protein & $351 \pm 20$ & $43 \pm 2$ & $5.8 \pm 0.1$ & $130 \pm 6$ & $1.34 \pm 0.33$ & $0.40 \pm 0.12$ & $36.0 \pm 4.0$ & $264 \pm 61$ & $73 \pm 32$ \\
\hline$P$ & $<0.05$ & NS & NS & NS & NS & $<0.001$ & $<0.001$ & $<0.02$ & $<0.05$ \\
\hline
\end{tabular}


to those in the rats in which clearances were performed, as confirmed by serum creatinine measurements. Histologic scoring for glomerular injury revealed similar values in rats maintained on 6 and $20 \%$ protein, determined at $9 \pm 2$ and $10 \pm 1$ respectively $(P=\mathrm{NS})$.

Short-term studies. Rats with established injury to remnant kidneys were matched for serum creatinine $(1.10 \pm 0.20$ vs. $1.07 \pm 0.10 \mathrm{mg} / \mathrm{dl}, P=\mathrm{NS})$. Those assigned to receive either a 6 or $20 \%$ protein diet exhibited similar body weights $(347 \pm 17$ vs. $332 \pm 14 \mathrm{~g}, P=\mathrm{NS})$, and urinary total protein excretory rates ( $65 \pm 15$ vs. $83 \pm 16 \mathrm{mg} / 24 \mathrm{~h}, P=$ NS) (all values $6 \%$ vs. $20 \%$ ). Daily food intake, the mean of four determinations, tended to be greater on the $20 \%$ diet but was not significantly different between the two groups, $15.2 \pm 1.1$ and $17.1 \pm 1.0 \mathrm{~g} / 24 \mathrm{~h}$ in the 6 and $20 \%$ protein-fed groups respectively.

2 wk later, at the time of clearance and micropuncture measurements, mean body weights in $6 \%$ protein-fed animals, while numerically lower than in the $20 \%$ fed animals, were not significantly different. Mean values for whole kidney GFR and renal plasma flow (RPF), $\overline{\mathrm{AP}}$, and the physical factors that determine glomerular ultrafiltration are shown in Table III. GFR and RPF in rats maintained on $6 \%$ protein diet, $0.59 \pm 0.11$ and $2.40 \pm 0.52 \mathrm{ml} / \mathrm{min}$ respectively, were not significantly different from the values in animals maintained on $20 \%$ protein, $0.50 \pm 0.1$ and $1.80 \pm 0.45 \mathrm{ml} / \mathrm{min}$ respectively. Mean arterial pressure was also comparable between the two dietary groups, $153 \pm 7 \mathrm{mmHg}$ in animals fed a $6 \%$ protein diet and $155 \pm 11 \mathrm{mmHg}$ in animals fed a $20 \%$ protein diet $(P=N S)$.

Single nephron filtration rates were not statistically different between the two dietary groups, measured at $106 \pm 11 \mathrm{nl} / \mathrm{min}$ in $6 \%$ protein-fed animals and $95 \mathrm{nl} / \mathrm{min}$ in $20 \%$ protein-fed animals. No statistically significant differences were noted in $C_{\mathrm{A}}$ $(6.1 \pm 0.2$ vs. $6.4 \pm 0.2 \mathrm{gm} / \mathrm{dl}) . Q_{\mathrm{A}}$ was substantially greater than typical values in normal rats but was not different in animals maintained on 6 and $20 \%$ protein diets respectively, $422 \pm 32$ vs. $347 \pm 33 \mathrm{nl} / \mathrm{min}$. However, the mean transcapillary hydraulic pressure difference $(\overline{\Delta P})$ in low protein-fed animals measured at $47 \pm 2 \mathrm{mmHg}$, was significantly lower than in higher proteinfed animals, determined at $66 \pm 4 \mathrm{mmHg}$. Unique values of $K_{\mathrm{f}}$ were calculable for both dietary groups because filtration disequilibrium $\left(\overline{\Delta P}>\pi_{\mathrm{E}}\right)$ was found in both dietary groups, that is, $47 \pm 2>33 \pm 2 \mathrm{mmHg}, P<0.01$ in $6 \%$ protein-fed animals and $66 \pm 4>37 \pm 2 \mathrm{mmHg}, P<0.01$, for $20 \%$ protein-fed animals. The values for $K_{f}$ for animals maintained on $6 \%$ protein was more than double the value for $K_{\mathrm{f}}$ obtained in animals maintained on $20 \%(0.094 \pm 0.016$ vs. $0.038 \pm 0.003 \mathrm{nl} / \mathrm{s}$ per $\mathrm{mmHg}$ ). Thus, after $2 \mathrm{wk}$ of a restricted dietary protein intake, the elevation in $K_{\mathrm{f}}$ counterbalanced the decrease in $\overline{\Delta P}$ found in animals maintained on $6 \%$ protein such that SNGFR was maintained at a level comparable to that exhibited in remnant animals maintained on $20 \%$ dietary protein.

Because $P_{\mathrm{T}}$ was similar in the two dietary groups, the lower $\overline{\Delta P}$ in animals with a restricted protein intake was due to a significantly lower $\bar{P}_{\mathrm{GC}}$ in $6 \%$ protein-fed animals, measured at $63 \pm 2 \mathrm{mmHg}$ as compared with the mean value of $81 \pm 4 \mathrm{mmHg}$ obtained in $20 \%$ protein-fed animals. The lower $\bar{P}_{\text {GC }}$ observed with restricted protein intake was the consequence of a lower $R_{\mathrm{E}}\left(0.59 \pm 0.06\right.$ vs. $1.05 \pm 0.15$ dynes-s-cm $\left.{ }^{-5} \times 10^{10}, P<0.05\right)$ in conjunction with similar $R_{\mathrm{A}}(0.94 \pm 0.05$ vs. $1.00 \pm 0.11$, dynes$\left.\mathrm{s}-\mathrm{cm}^{-5} \times 10^{10}, P=\mathrm{NS}\right)$ when compared with animals maintained on $20 \%$ protein. Thus, the lower $\bar{P}_{\mathrm{GC}}$ in animals on $6 \%$ protein resulted from a diminished efferent arteriolar tone.

In addition to these differences in glomerular hemodynamics, marked differences in macromolecular clearances were observed between the two dietary groups. Fractional clearances of albumin and IgG in animals maintained on $6 \%$ protein measured at $172 \pm 27 \times 10^{-5}$ and $56 \pm 8 \times 10^{-5}$, were markedly lower than values obtained in animals maintained on $20 \%$ protein determined at $626 \pm 144 \times 10^{-5}$ and $205 \pm 38 \times 10^{-5}$, respectively.

Mean scores for glomerular injury in animals maintained on $6 \%$ protein and $20 \%$ protein determined at $9 \pm 2$ and $10 \pm 3$ respectively, were not statistically different. Thus, the differences in macromolecular clearances and glomerular hemodynamics observed with short-term alteration of dietary protein intake were not accompanied by differences in glomerular injury as determined by light microscopy.

\section{Discussion}

The institution of a low protein diet before, or at the time of, partial renal ablation significantly alters the severity of renal damage in the remnant kidney $(2,7-10)$. Adaptive increments in single nephron filtration rates, transcapillary hydraulic pressures, and glomerular capillary plasma flow are markedly blunted, glomerular ultrastructural changes are attenuated, and glomerular permselectivity is less impaired, with dietary protein restriction $(2,7)$. The diminution of intrarenal pressures and flows has been proposed as the beneficial effect of this dietary manipulation $(2,11,12)$. Subtotally nephrectomized rats, chronically maintained on a low dietary protein intake from the onset of renal injury develop less proteinuria and glomerular sclerosis $(8,10)$ and have lower mortality rates $(9,10)$ as compared with remnant animals maintained on a high dietary protein intake. These and other observations $(1,12)$ have lent enthusiasm to the view that dietary protein restriction retards the progression of chronic renal disease (12-14). However, these studies in the remnant kidney model do not address the equally pertinent

Table III. Summary of Clearance and Micropuncture Data 2 wk after Diet Change

\begin{tabular}{|c|c|c|c|c|c|c|c|c|c|c|c|}
\hline & WT & HCT & $\overline{A P}$ & $\overline{\mathrm{P}}_{\mathrm{CC}}$ & $\mathbf{P}_{\mathbf{T}}$ & $\mathbf{P}_{\mathrm{E}}$ & $\overline{\Delta \mathbf{P}}$ & $\mathrm{C}_{\mathrm{A}}$ & $\mathrm{C}_{\mathrm{E}}$ & $\pi_{A}$ & $\pi_{\mathrm{E}}$ \\
\hline$n=5$ & $g$ & $\%$ & $m m H g$ & $m m H g$ & $\mathrm{mmHg}$ & $m m H g$ & $m m H g$ & $\mathrm{~g} / 100 \mathrm{ml}$ & $\mathrm{g} / 100 \mathrm{ml}$ & $\mathrm{mmHg}$ & $\mathrm{mmHg}$ \\
\hline $6 \%$ protein & $321 \pm 5$ & $44 \pm 2$ & $152 \pm 7$ & $63 \pm 2$ & $16 \pm 1$ & $16 \pm 1$ & $47 \pm 2$ & $6.1 \pm 0.2$ & $8.2 \pm 0.3$ & $21 \pm 1$ & $33 \pm 3$ \\
\hline $20 \%$ protein & $342 \pm 17$ & $42 \pm 1$ & $155 \pm 11$ & $81 \pm 4$ & $15 \pm 1$ & $18 \pm 2$ & $66 \pm 4$ & $6.4 \pm 0.2$ & $9.0 \pm 0.2$ & $22 \pm 1$ & $37 \pm 2$ \\
\hline$P$ & NS & NS & NS & $<0.01$ & NS & NS & $<0.01$ & NS & NS & NS & NS \\
\hline
\end{tabular}


clinical question of whether this dietary manipulation would still protect against renal injury if instituted after renal structural damage has already occurred.

Our study demonstrates that dietary protein restriction imposed after renal injury is established retards the decline in renal function and, in fact our long-term studies are the first to demonstrate that GFRs as measured by inulin clearances are higher in remnant animals maintained on lower protein intake. Further evidence for the protective effects of dietary protein restriction is derived from the markedly reduced indices of renal injury, that is, urinary total protein excretory rates, fractional clearances of albumin and IgG in remnant animals maintained on $6 \%$ protein. It is likely that these reductions in fractional clearances of albumin and IgG result from preservation of the size-selective properties of the glomerular capillary. The work of Myers and others have demonstrated that the high fractional clearances of IgG found in assorted glomerulopathies are consistent with the presence of a subpopulation of enlarged pores in the glomerular filtration barrier that are readily traversed by IgG molecules $(22$, 23). Whereas such preservation in size selectivity may also contribute to the reduction in fractional clearance of albumin in animals on a restricted protein intake, repair of a charge-selective defect also likely contributes $(7,22)$.

The protective effect of dietary protein restriction could not be ascribed to a reduction of systemic arterial hypertension because repeated measurements of conscious systolic arterial pressure as well as determination of mean arterial pressure during clearance studies failed to reveal any significant difference between the two dietary groups. Dietary protein restriction appears unique in this regard; other measures that protect against renal injury in the remnant model, such as enalapril (24), heparin (25), antiplatelet agents (26), and thromboxane synthetase inhibitors (27), all significantly reduce systemic arterial pressure. The lack of an effect of dietary protein restriction on systemic arterial pressure however, does not preclude an important effect on remnant nephron hemodynamics (2).

To examine whether an alteration of intrarenal hemodynamics occurs if dietary protein restriction is imposed after injury is established, we performed micropuncture studies 2 wk after dietary protein restriction in rats with established injury. Both groups were stratified to similar levels of renal function at the time of dietary assignment. When studied 2 wk later, whole kidney GFR and renal plasma flow were similar in the two dietary groups, as were the single nephron filtration rates. No differences were detected in afferent arteriolar protein concentration or glomerular capillary plasma flow. However, the mean transcapillary hydraulic pressure gradient was significantly reduced in rats maintained on a lower dietary protein intake, an effect that would tend to lower single nephron filtration rates. Offsetting this effect was a greater ultrafiltration coefficient in the low pro- tein-fed rats. Filtration pressure disequilibrium was observed in both dietary groups and is attributable to the high glomerular capillary plasma flow rates (28). Unique values of glomerular capillary ultrafiltration coefficient were thus calculable (28). Such determinations demonstrated that the ultrafiltration coefficient in animals maintained on $6 \%$ protein was more than twice the value obtained in animals maintained on $20 \%$ protein. Thus, the tendency for lower transcapillary hydraulic pressure to decrease single nephron filtration rates in animals fed $6 \%$ protein was nullified by the higher ultrafiltration coefficient such that both dietary groups exhibited comparable values for single nephron filtration rates.

The lower transcapillary hydraulic pressure gradient and glomerular capillary hydraulic pressure in the protein-restricted animals were the result of decreased efferent arteriolar resistance. In view of the relatively short period in which dietary protein restriction led to changes in efferent arteriolar resistance and ultrafiltration coefficient, it is likely that the mechanism underlying these changes is of a functional rather than structural nature. Indeed, our light microscopic studies on the severity of glomerular injury revealed no differences between the two dietary groups. A variety of hormonal substances have been shown to regulate efferent arteriolar tone (29) and ultrafiltration coefficient $(30,31)$ and it is quite likely that altering dietary protein intake may alter intrarenal levels of vasoactive hormones $(12,13)$. Dietary protein intake is directly related to systemic plasma renin activity (32), an effect that could lead to greater intrarenal levels of angiotensin II in animals on higher protein diets and thus, at least partially, explain the greater efferent arteriolar resistance and lower ultrafiltration coefficient seen in rats maintained on a higher protein intake (31).

In addition to these differences in glomerular hemodynamics, marked reductions in the fractional clearances of albumin and IgG were seen with dietary protein restriction. The determinants of glomerular ultrafiltration influence the fractional clearances of macromolecules (33). Because there were no significant differences in afferent arteriolar protein concentration and glomerular capillary plasma flow between the two dietary groups, no differences in the fractional clearances of albumin and IgG would be expected on these grounds. Transcapillary hydraulic pressure gradients $>45 \mathrm{mmHg}$, which were achieved in both our dietary groups, are predicted to exert negligible effects on fractional clearances of macromolecules (33), assuming that such heightened gradients exert no direct effects on the permeability characteristics of the capillary. Increases in the ultrafiltration coefficient are expected to lead to increased fractional clearances in albumin and IgG (33). The ultrafiltration coefficient was increased in the animals maintained on $6 \%$ protein, the dietary group that demonstrated lower fractional clearances of albumin and IgG. Given these findings, and the predictions based on

\begin{tabular}{|c|c|c|c|c|c|c|c|c|c|c|}
\hline GFR & RPF & FF & SNGFR & $Q_{\text {A }}$ & $R_{\wedge} \times 10^{10}$ & $R_{\mathrm{E}} \times 10^{10}$ & $R_{\mathrm{TA}} \times 10^{10}$ & $K_{\mathrm{f}}$ & $\theta_{\mathrm{ALB}} \times 10^{-5}$ & $\theta_{\mathrm{LGG}} \times 10^{-5}$ \\
\hline $\mathrm{ml} / \mathrm{min}$ & $\mathrm{ml} / \mathrm{min}$ & $\mathrm{ml} / \mathrm{min}$ & $n l / \min$ & $n l / \min$ & dyn-s-cm ${ }^{-s}$ & $d y n-s-c^{-5}$ & $d y n-s-\mathrm{cm}^{-5}$ & $n l / s-m m H g$ & & \\
\hline $0.59 \pm 0.11$ & $2.40 \pm 0.52$ & $0.25 \pm 0.02$ & $106 \pm 11$ & $422 \pm 32$ & $0.94 \pm 0.05$ & $0.59 \pm 0.06$ & $1.53 \pm 0.09$ & $0.094 \pm 0.016$ & $172 \pm 27$ & $56 \pm 8$ \\
\hline $0.50 \pm 0.1$ & $1.80 \pm 0.45$ & $0.27 \pm 0.01$ & $95 \pm 10$ & $347 \pm 33$ & $1.00 \pm 0.11$ & $1.05 \pm 0.15$ & $2.05 \pm 0.24$ & $0.038 \pm 0.003$ & $626 \pm 144$ & $205 \pm 38$ \\
\hline NS & NS & NS & NS & NS & NS & $<0.01$ & 0.06 & $<0.02$ & $<0.01$ & $<0.01$ \\
\hline
\end{tabular}


alterations in the determinants of glomerular filtration, it is likely that the improvements in intrinsic size- and charge-permselectivity with dietary protein restriction overrode the competing effect of elevation of ultrafiltration coefficient, thereby leading to decreased clearance of macromolecules.

The hemodynamic effects we have observed in our micropuncture studies are different from the hemodynamic effects observed with reduction in dietary protein intake in healthy animals with intact kidneys (34), and in animals with reduced renal mass when dietary protein restriction is applied at the time renal mass is reduced (2). In the normal growing rat with intact kidneys, dietary protein restriction over 4 mo leads to decreased SNGFR due to decreases in glomerular plasma flow and in the glomerular ultrafiltration coefficient, the latter ascribed to a reduction in the glomerular cross sectional area (34). In the remnant kidney model, decreased dietary protein intake applied at the time renal mass is reduced, blunts the adaptive increase in single nephron filtration rates due to its effects on glomerular plasma flow and the transcapillary hydraulic pressure gradient (2), and reduces the structural hypertrophy that attends reduction of renal mass $(8,35)$. In our studies, we applied short-term dietary protein restriction $6 \mathrm{wk}$ after the reduction of renal mass. Thus, our studies in the remnant kidney model focused on the effects of dietary protein restriction imposed after the structural hypertrophic response, as well as the glomerular hemodynamic response to ablation of renal mass, were fully developed. In such a setting we observed that dietary protein restriction led to no significant alteration in remnant kidney GFR and single nephron filtration rate, the latter due to offsetting effects of a rise in glomerular ultrafiltration coefficient and a fall in transcapillary hydraulic pressure. Thus, the effect of dietary protein restriction in the remnant kidney model may be influenced by the extent to which adaptive alterations in glomerular hemodynamics and/ or renal compensatory growth are already established.

Interestingly, in established human renal insufficiency a similarly blunted effect of dietary protein restriction on GFR has been observed (36-38). In such patients there is evidence that the capacity for alteration in dietary protein intake to elicit changes in GFR is inversely proportional to the extent to which renal function is decreased below normal $(36,37)$ : thus, the lower the basal GFR, the more attenuated is the alteration in GFR with dietary protein manipulation $(36,37)$. This has given rise to the concept of renal functional reserve, which is viewed as a measure of the capacity of GFR to rise under certain stimuli such as a protein load (36). It is conceivable that when renal injury is severe and longstanding a maximal adaptive response occurs in remnant glomeruli. In such settings, one would anticipate a relative insensitivity of GFR to dietary protein manipulation.

The major significance of the micropuncture study is that animals maintained on $6 \%$ protein diet exhibit lower glomerular capillary pressure yet similar glomerular capillary plasma flow and single nephron filtration rates when compared with the animals maintained on $20 \%$ protein, and it is this protein restricted group that demonstrate greater preservation of renal function in the long term study. Whereas there is a large body of evidence that elevated glomerular capillary pressure, filtration rate, and plasma flow in concert inflict glomerular injury $(1,11,12)$, there is increasing evidence that increased glomerular capillary pressure per se provokes glomerular damage. For example, in the remnant model chronic treatment with a converting enzyme inhibitor markedly decreases intracapillary hypertension without affecting glomerular hyperperfusion, and leads to less proteinuria and glomerular sclerosis (24). A similar pattern of results has also been reported with converting enzyme inhibition in experimental diabetes mellitus (39). In the uninephrectomized desoxycorticosterone-salt hypertensive rat, which manifests significant glomerular damage and proteinuria as compared with the uninephrectomized control, glomerular capillary pressure but not glomerular capillary plasma flow is increased (3). Furthermore, treating these hypertensive rats with a combination of hydrochlorothiazide, hydralazine, and reserpine such that the systemic pressure is normalized, does not reduce the elevated glomerular capillary pressure and fails to protect against glomerular injury (40). Finally, rats subjected to repetitive pregnancy, a state that has been characterized as having glomerular hyperperfusion but not glomerular hypertension, fail to exhibit morphologic evidence of glomerular injury or increased urinary protein excretory rates (41). Thus, glomerular pressure per se is a critical determinant of glomerular injury. Our study demonstrates that the preservation of renal function with the institution of dietary protein restriction after renal injury is established follows upon reduction of glomerular capillary hydraulic pressure without reduction in the augmented single-nephron filtration rate or plasma flow.

Our findings in the remnant kidney model are germane to the current attempts to retard the progression of human renal insufficiency with dietary protein restriction. Both short- as well as long-term dietary protein restriction in humans with established chronic renal insufficiency have demonstrated remarkably similar findings to ours in the remnant kidney model $(38,42)$. Dietary protein restriction over $10 \mathrm{~d}$ in humans with assorted chronic glomerulopathies reduces fractional clearances of albumin and IgG in the absence of any significant alteration of systemic mean arterial pressure or whole kidney filtration rates and plasma flow (38). Also, a recent long term, randomized, prospective study in established human renal insufficiency demonstrated that dietary protein restriction reduces rates of progression of renal insufficiency, and proteinuria, without any significant effect on systemic arterial pressure (42). We suggest that the diminished glomerular capillary hydraulic pressure that occurs in the remnant kidney model with dietary protein restriction also occurs in established human renal insufficiency when protein intake is reduced. This finding in the rat points out the hazards of inferring intra-renal pressures from measurements of flows.

\section{Acknowledgments}

We thank K. S. Gustafson for expert technical assistance and L. Chmielewski for expert secretarial assistance.

This work was supported by a U. S. Public Health Service Grant AM31437 (to T. H. Hostetter), Individual National Research Service Award, AM07165 (to K. A. Nath), and a grant from the National Kidney Foundation of the Upper Midwest (to K. A. Nath and T. H. Hostetter), and the Minnesota Medical Foundation (to K. A. Nath and T. H. Hostetter).

\section{References}

1. Hostetter, T. H., and B. M. Brenner. 1981. Glomerular adaptations to renal injury. In Contemporary issues in Nephrology. B. M. Brenner and J. H. Stein, editors. Churchill Livingstone, Inc., New York. 1-27.

2. Hostetter, T. H., J. L. Olson, H. G. Rennke, M. A. Venkatachalam, and B. M. Brenner. 1981. Hyperfiltration in remnant nephrons: a po- 
tentially adverse response to renal ablation. Am. J. Physiol. 241:F85F93.

3. Dworkin, L. D., T. H. Hostetter, H. G. Rennke, and B. M. Brenner. 1984. Hemodynamic basis for glomerular injury in rats with desoxycorticosterone-salt hypertension. J. Clin. Invest. 73:1448-1461.

4. Neugarten, J., H. D. Feiner, R. G. Schacht, and D. S. Baldwin. 1983. Amelioration of experimental glomerulonephritis by dietary protein restriction. Kidney Int. 24:595-601.

5. Friend, P. S., G. Fernandes, R. A. Good, A. F. Michael, and E. J. Yunis. 1978. Dietary restriction early and late: effects on the nephropathy of the NZB $\times$ NZW mouse. Lab. Invest. 38:629-632.

6. Wen, S. F. 1983. Effect of low protein diet on experimental diabetic nephropathy. Clin. Res. 31:444. (Abstr.)

7. Olson, J. L., T. H. Hostetter, H. G. Rennke, B. M. Brenner, and M. A. Venkatachalam. 1983. Altered glomerular permselectivity and progressive sclerosis following extreme ablation of renal mass. Kidney Int. 22:112-126.

8. Hostetter, T. H., T. W. Meyer, H. G. Rennke, and B. M. Brenner. 1986. Chronic effects of dietary protein on renal structure and function in the rat with intact and reduced renal mass. Kidney Int. In press.

9. Kleinknecht, C., I. Salusky, M. Broyer, and M. C. Gubler. 1979. Effect of various protein diets on growth, renal function, and survival of uremic rats. Kidney Int. 15:534-541.

10. El-Nahas, A. M., H. Paraskevakou, S. Zoob, A. J. Rees, and D. J. Evans. 1983. Effect of dietary protein restriction on the development of renal failure after subtotal nephrectomy in rats. Clin. Sci. (Lond.). 65: 399-406.

11. Hostetter, T. H., H. G. Rennke, and B. M. Brenner. 1982. The case for intrarenal hypertension in the initiation and progression of diabetic and other glomerulopathies. Am. J. Med. 72:375-380.

12. Brenner, B. M., T. W. Meyer, and T. H. Hostetter. Dietary protein intake and the progressive nature of kidney disease: the role of hemodynamically mediated glomerular injury in the pathogenesis of progressive glomerular sclerosis in aging, renal ablation and intrinsic renal disease. N. Engl. J. Med. 307:652-657.

13. Klahr, S., J. Buerkert, and M. L. Purkerson. 1983. Role of dietary factors in the progression of chronic renal disease. Kidney Int. 24:579587.

14. Mitch, W. E. 1984. The influence of the diet on the progression of renal insufficiency. Ann. Rev. Med. 35:249-264.

15. Henry, J. B. 1984. Clinical Diagnosis and Management by Laboratory Methods. 17th Edition. W. B. Saunders, Co., Philadelphia. 136.

16. Henry, J. B. 1984. Clinical Diagnosis and Management by Laboratory Methods 17th Edition. W. B. Saunders, Co., Philadelphia. 405.

17. Ichikawa, I., D. A. Maddox, M. C. Cogan, and B. M. Brenner. 1978. Dynamics of glomerular ultrafiltration in envolemic Munich-Wistar rats. Renal Physiol. 1:121-131.

18. Gertz, K. H., J. A. Mangos, G. Braun, and H. D. Pagel. 1966. Pressure in the glomerular capillaries of the rat kidney and its relation to arterial pressure. Pfluegers Arch. 288:369-374.

19. Landis, E. M., and J. R. Pappenheimer. 1964. Exchange of substances through the capillary walls. In Handbook of Physiology. Section 2, Circulation. J. Orloff and R. Berliner, editors. Williams \& Wilkins, Baltimore. 961-1034.

20. Deen, W. M., C. R. Robertson, and B. M. Brenner. 1972. A model of glomerular ultrafiltration in the rat. Am. J. Physiol. 223:11781183.

21. Viberti, G., D. Mackintosh, R. W. Bilous, J. C. Pickup, and H. Keen. 1982. Proteinuria in diabetes mellitus: role of spontaneous and experimental variation of glycemia. Kidney Int. 21:714-720.

22. Myers, B. D., T. B. Okarma, S. Friedman, C. Bridges, J. Ross, S. Asseff, and W. M. Deen. 1982. Mechanisms of proteinuria in human glomerulonephritis. J. Clin. Invest. 70:732-746.

23. Friedman, S., S. Strober, E. H. Field, E. Silverman, and B. D.
Myers. 1984. Glomerular capillary wall function in human lupus nephritis. Am. J. Physiol. 246:F580-F591.

24. Anderson, S., T. W. Meyer, H. G. Rennke, and B. M. Brenner. 1985. Control of glomerular hypertension limits glomerular injury in rats with reduced renal mass. J. Clin. Invest. 76:612-619.

25. Purkerson, M. L., P. E. Hoffsten, and S. Klahr. 1976. Pathogenesis of the glomerulopathy associated with renal infarction in rats. Kidney Int. 9:407-417.

26. Purkerson, M. L., J. H. Joist, J. Yates, and S. Klahr. 1984. Role of hypertension and coagulation in the glomerulopathy of rats with subtotal renal ablation. Proc. IX Int. Cong. Nephrology, Los Angeles. 359A. (Abstr.)

27. Purkerson, M. L., J. H. Joist, J. Yates, A. Valdes, A. Morrison, and S. Klahr. 1985. Inhibition of thromboxane synthesis ameliorates the progressive kidney disease of rats with subtotal renal ablation. Proc. Natl. Acad. Sci. USA. 82:193-197.

28. Deen, W. M., J. L. Troy, C. R. Robertson, and B. M. Brenner. 1973. Dynamics of the glomerular ultrafiltration in the rat. IV. Determination of the ultrafiltration coefficient. J. Clin. Invest. 52:1500-1508.

29. Edwards, R. M. 1983. Segmental effects of norepinephrine and angiotensin II on isolated renal microvessels. Am. J. Physiol. 244:F526F534.

30. Schor, N., I. Ichikawa, and B. M. Brenner. 1981. Mechanisms of action of various hormones and vasoactive substances on glomerular ultrafiltration in the rat. Kidney Int. 20:442-451.

31. Dworkin, L. D., I. Ichikawa, and B. M. Brenner. 1983. Hormonal modulation of glomerular function. Am. J. Physiol. 244:F95-F104.

32. Paller, M. S., and T. H. Hostetter. 1985. Dietary protein increases plasma renin activity and reduces pressor reactivity to angiotensin II. Clin. Res. 33:554A. (Abstr.)

33. Deen, W. M., M. P. Bohrer, and B. M. Brenner. 1979. Macromolecular transport across glomerular capillaries: application of pore theory. Kidney Int. 16:353-365.

34. Ichikawa, I., M. L. Purkerson, S. Klahr, J. L. Troy, M. MartinezMaldonado, and B. M. Brenner. 1980. Mechanism of reduced glomerular filtration rate in chronic malnutrition. J. Clin. Invest. 65:982-988.

35. Schoolwerth, A. C., R. S. Sandler, P. M. Hoffman, and S. Klahr. 1975. Effect of nephron reduction and dietary protein content on renal ammoniagenesis in the rat. Kidney Int. 7:397-404.

36. Bosch, J. P., A. Saccaggi, A. Lauer, C. Ronco, M. Belledonne, and S. Glabman. 1983. Renal functional reserve in humans: effects of protein intake on glomerular filtration rate. Am. J. Med. 75:943-950.

37. Rodriguez-Iturbe, B., J. Herrera, and R. Garcia. 1985. Response to acute protein load in kidney donors and in apparently normal postacute glomerulonephritis patients: evidence for glomerular hyperfiltration. Lancet. ii:461-464.

38. Rosenberg, M. E., B. L. Thomas, J. E. Swanson, and T. H. Hostetter. 1986. The effect of protein intake on glomerular function in human renal disease. Kidney Int. 29:325. (Abstr.)

39. Zatz, R., T. W. Meyer, B. R. Dunn, S. Anderson, R. L. DeGraphenreid, J. L. Noddin, A. W. Nunn, J. L. Troy, and B. M. Brenner. 1985. Lowering arterial pressure limits glomerular hypertension and albuminuria in experimental diabetes. Kidney Int. 27:252. (Abstr.)

40. Dworkin, L. D., H. D. Feiner, and J. Randazzo. 1985. Evidence for hemodynamically mediated glomerular injury despite antihypertensive therapy in rats with desoxycorticosterone-salt (DOC-salt) hypertension. Kidney Int. 27:189. (Abstr.)

41. Baylis, C., and H. G. Rennke. 1985. Renal hemodynamics and glomerular morphology in repetitively pregnant aging rats. Kidney Int. 28:140-145.

42. Rosman, J. B., S. Meijer, W. J. Sluiter, P. M. Ter Wee, T. P. M. Piers-Becht, and A. J. M. Donker. 1984. Prospective randomised trial of early dietary protein restriction in chronic renal function. Lancet. ii: 1291-1296. 